\title{
ИСПОЛЬЗОВАНИЕ ТЕХНОЛОГИИ КОНТЕКСТНОГО ОБУЧЕНИЯ В ПРЕПОДАВАНИИ ВОПРОСОВ ИНФЕКЦИОННОЙ БЕЗОПАСНОСТИ В ДОПОЛНИТЕЛЬНОМ ОБРАЗОВАНИИ МЕДИЦИНСКОГО УНИВЕРСИТЕТА
}

\author{
Сметанин Виктор Николаевич \\ кандидат медицинскх наук, доцент, \\ дочент кафедры эпидемиологии Рязанского государственного \\ медицинского университета имени академика И.П. Павлова, \\ 390026 г. Рязань, ул. Высоковольтная, д. 9 \\ Кирюшин Валерий Анатольевич \\ доктор медицинских наук, профессор, \\ заведующий кафедрой профильных гигиенических дисияиплин с \\ курсом гигиены, эпидемиологии и организаџии госсанэпидслужбы ФДПО \\ Рязанского государственного медицинского университета \\ имени академика И.П. Павлова, \\ 390026 г. Рязань, ул. Высоковольтная, д. 9
}

\begin{abstract}
Аннотация. Компетентностный подхода в системе высшего профессионального образования обеспечивает улучшение взаимодействие с рынком труда и повышение конкурентоспособности специалистов, что требует обновление содержания образования и повышение качества профессионального обучения.

Annotation. A competent approach in the higher vocational education system provides an improved interaction with the labor market and improved the competitiveness of professionals, which requires updating the content of education and improving the quality of vocational training.

Ключевые слова: технологии, компетентностный подход, инфекционная безопасность, дополнительное профессиональное образование

Keywords: technology, competent approach, infectious safety, additional vocational education
\end{abstract}

Внедрение компетентностного подхода в систему высшего профессионального образования направлено на улучшение взаимодействия с рынком труда, повышение конкурентоспособности специалистов, обновление содержания, методологии и соответствующей среды обучения.

Основная цель профессионального образования - подготовка квалифицированного специалиста соответствующего уровня и профиля, конкурентоспособного на рынке труда, компетентного, свободно владеющего своей профессией и ориентирующегося в смежных областях деятельности, готового к постоянному профессиональному росту, социальной и профессиональной мобильности.

В качестве основания Федерального государственного стандарта (ФГОС) высшего образования по специальности 32.05.01. «Медико-профилактическое дело» (уровень специалитета) выступает компетентностный подход, направленный на обновление содержания образования и повышение качества профессионального обучения.

Смена методологических идей оказала влияние на изменение понятийного аппарата. Вместо привычных «знаний», «умений», «навыков» появились новые термины: «компетенция» и «компетентность».

Понятие «компетентность» подразумевает готовность (подготовленность) человека к выполнению той или иной социальной роли: профессионала, члена общества, гражданина и т. д. С этих позиций компетентность есть результат образования, а, следовательно, и цель, достижение которой обеспечивается реализацией требований стандарта.

Понятие «компетентность» следует отличать от понятия «компетенции», которые представляют обобщенные способы действий, обеспечивающие продуктивное выполнение профессиональной или иной деятельности. То есть компетенции обнаруживаются и проявляются в конкретных ситуациях, социальных и профессиональных обстоятельствах [1, с. 12-13].

В теории компетентностного подхода выделяют ключевые и функциональные компетенции.

Под ключевыми понимаются компетенции, необходимые для жизнедеятельности человека и связанные с его успехом в профессиональной деятельности в быстроизменяющемся обществе [1,2,3,4]. В этом смысле они становятся универсальными, широкого спектра действия. Э.Ф. Зеер [5] считает более правильно их называть базовыми компетенциями, поскольку они многофункциональны, междисциплинарны, надпредметны и первичны по отношению к другим. В стандартах третьего поколения ключевые компетенции обозначены как общие компетенции (ОК).

Функциональные (специальные) компетенции представляют собой совокупность характеристик определенной профессиональной деятельности и представляют собой набор функций конкретного рабочего места. В стандарте данная группа компетенций обозначена как профессиональные компетенции (ПК). 
Структурным элементом стандартов третьего поколения является не предмет, а образовательная область, представляемая в виде профессиональных модулей и междисциплинарных курсов, направленных на освоение обучающимися конкретных видов профессиональной деятельности. В свою очередь, структурными элементами профессиональных модулей становятся профессиональные (ПК) и общие (ОК) компетенции.

Методологический подход, положенный в основу новых стандартов, обусловливает изменения не только в построении образовательного процесса, но и оказывает влияние на использование педагогами иных форм, методов обучения и воспитания, поскольку формирование компетенций невозможно в рамках традиционных технологий, направленных на формирование знаний, умений и навыков.

На современном этапе развития общества и модернизации образования необходимо, чтобы слушатели были ориентированы на практическое применение полученных знаний, на анализ и критическое осмысление поступающей информации, на умения принимать профессиональные решения на основе творческой переработки полученных знаний. В связи с этим появляется необходимость использования активных и методов, форм и технологий обучения, обеспечивающих интенсивное развитие личности слушателя и преподавателя [6].

Прежде чем внедрять эту технологию в процесс обучения была проделана большая предварительная работа по изучению сущности технологии, опыта работы других образовательных учреждений, возможности использования технологии в зависимости от особенностей дисциплины. Результатом этой работы можно считать разработанные методические подходы к использованию технологии контекстного обучения, которые и будут представлены ниже.

Традиционное обучения ориентировано на усвоение знаковой учебной информации и чем больше ее усвоено, тем выше считается уровень образованности. В традиционной практике слушатель получает знания, которые оторваны от смыслообразующих контекстов его будущей специальности. Сейчас происходит стремительное обновление оборудования и технологий оказания медицинской помощи, а мы учим как бы с опозданием, отстаем от динамики в развитии специальности. Обучение же тогда ценно, когда оно учит с опережением, готовит специалиста к завтрашнему дню.

Кроме того, цели, которые ставятся слушателям при обучении, задаются обществом (требования ФГОС), преподавателем, но не самим слушателем. Поэтому учение и теряет для них смысл, ведь задачи и цели поставлены не самими слушателями, а навязаны извне.

В технологии контекстного обучения необходимо также уяснить разницу между содержанием обучения и содержанием образования. Содержание обучения определяется ФГОС по специальности, учебными планами и программами. В отличие от содержания обучения содержание образования отражает уровень развития личности, предметной и социальной компетентности слушателя, который формируется в процессе обучения. Меняется «образ» личности и цель образования - развитие личностного потенциала. Базовым понятием контекстного обучения является категория контекста. Контекст связан с понятием «ситуация», т. е. системой условий, побуждающих субъекта к проявлению активности. В ситуацию включаются и внешние условия, и сам субъект, и те люди, с которыми он контактирует.

Прежде чем приступить к действию, человек старается собрать как можно больше контекстной информации. Если у человека нет образцов поведения, зафиксированных в определенных контекстах, например поведения в определенных производственных ситуациях, то он испытывает дискомфорт, даже страх и неумение спрогнозировать свои действия. Прогнозирование как необходимое умение основано на предвосхищении действий хотя бы на шаг. Следовательно, контекст может активизировать мышление слушателя и вводить его в состояние проблемной или творческой ситуации.

Учебный процесс в университете является одним из проявлений социальной практики. Следовательно, контексты жизни и будущей трудовой деятельности медицинского работника должны наполнить учебу личностным смыслом, определить меру включенности в познавательный процесс. Отсюда меняется и основная цель деятельности преподавателя: не обучение, а формирование целостной модели профессиональной деятельности слушателя.

Предмет учебной деятельности для слушателя всегда абстрактен, им являются тексты, схемы, макеты, методические указания. В реальном же предмете будущей профессиональной деятельности знания даны в контексте технологических процессов и ситуаций. Продуктивное мышление - это обращение к новому, к тем неизвестным, нестандартным и проблемным ситуациям, которые возникнут у него в производственной деятельности. Следовательно, информация на занятии должна даваться в контексте будущей деятельности, с направленностью будущего профессионального использования: где, когда и как можно применить эти знания?

Одним из условий, создающим оптимальный процесс обучения по вопросам инфекционной безопасности является вовлечение обучающихся в определение своих собственных потребностей в знаниях по этому разделу, что стимулирует внутреннюю мотивацию к получению знаний и навыков.

Таким образом, слушателю задаются рамки его профессионального труда. Основой взаимодействия преподавателя и слушателя становится ситуация во всей ее предметной и социальной неоднозначности. Именно в ходе анализа ситуаций, деловых и учебных игр слушатель формируется как специалист и член будущего коллектива. 
В технологии контекстного обучения используются три базовые формы деятельности: учебная деятельность с ведущей ролью лекций и семинаров; квазипрофессиональная - игры, тренинги; учебно-профессиональнаяУИРС, производственная практика.

В соответствии с этими формами можно реализовать три модели обучения. Модели первого типа включают систему заданий, предполагающих работу с текстом и переработку знаковой информации. Единицей работы студента являются действия слушания и говорения, чтение, письмо. В моделях второго типа учебные задания будут выходить за рамки знаковой информации и соотносится с будущей профессиональной деятельностью. В этом случае единицей работы оказывается предметное действие. Учебная деятельность слушателя опирается на контекст. В моделях же третьего типа задания выполняются в совместных, коллективных формах. Такие совместные поиски решения проблемы формируют опыт коллективной работы в будущей профессиональной среде. Эта модель реализуется в деловых и учебных играх, УИРС, в выполнении профессиональной задачи на междисциплинарном экзамене.

Таким образом, образование в технологии контекстного обучения предполагает два компонента: предметное содержание, которое обеспечивает профессиональную компетентность слушателя, и социальное, обеспечивающее способность работать в коллективе, быть коммуникабельной и социально зрелой личностью.

На семинарских занятиях изучаются директивные документы, отражающие вопросы инфекционной безопасности и инфекционного контроля в условиях деятельности медицинских организаций.

При решении ситуационных задач слушатели самостоятельно оценивают состояние инфекционной безопасности на конкретных примерах и разрабатывают меры по предупреждению распространения внутрибольничных инфекций.

Необходимость внедрения новых форм постдипломного образования определяется тем, что при существующей системе обучения полученные знания плохо трансформируются в умения и практику применения навыков по инфекционной безопасности и профилактике ИСМП и улучшению результатов лечения больных.

Сочетание познавательного интереса и позитивной мотивации, характерное для контекстного обучения, способствует трансформации познавательных мотивов в профессиональные, что ведет к постепенному превращению учебной деятельности в реальную предметную деятельность.

Таким образом, формирование профессиональной компетентности в постдипломном образовании возможно посредством внедрения технологии контекстного обучения.

\section{Библиография}

1.Безюлева Г. В. Профессиональная компетентность: аспекты формирования. М.: МПСИ, ФИРО, 2005. 82 с.

2.Вербицкий А. А. Контекстно-компетентностный подход к модернизации образования // Высшее образование в России. 2010. № 5. С. 32-37.

3.Вербицкий А. А., Ларионова О.Г. Личностный и компетентностный подходы в образовании: проблемы интеграции. М.: Логос, 2009. 336 с.

4. Вербицкий, А. А. Контекстное обучение: теория и технологии / Новые методы и средства обучения.- 2009.№2 .- С 51-54

5.Зеер Э. Ф., Павлов А. М. Модернизация профессионального образования:

компетентностный подход. М.: Изд-во МПСИ, 2005. $211 \mathrm{c.}$

6. Лаврентьев, Г. В. Инновационные обучающие технологии в профессиональной подготовке специалистов / Г. В. Лаврентьев, Н. Б. Лаврентьева, Н. А. Неудахина. - Барнаул: Изд-во АлтГУ, 2004. - 184 с.

7. Концепция Федеральной целевой программы развития образования на 2016 - 2020 годы (утв. распоряжением Правительства РФ от 29 декабря 2014 г. № 2765-p). Электронный доступ. URL: http://www.garant.ru/products/ipo/prime/doc/55070647/

8. Троянская С.Л. Основы компетентностного подхода в высшем образовании: учебное пособие. - Ижевск: Издательский центр «Удмуртский университет», 2016 - 176 с.

9. Федоров А.Э., Компетентностный подход в образовательном процессе /А.Э.Федоров, С.Е. Метелев, А.А.Соловьев, Е.В. Шлякова-Омск-.2012.- 210 с. 


\title{
ИСПОЛЬЗОВАНИЕ ТЕХНОЛОГИИ КОНТЕКСТНОГО ОБУЧЕНИЯ В ПРЕПОДАВАНИИ ВОПРОСОВ ИНФЕКЦИОННОЙ БЕЗОПАСНОСТИ В ДОПОЛНИТЕЛЬНОМ ОБРАЗОВАНИИ МЕДИЦИНСКОГО УНИВЕРСИТЕТА
}

\author{
Сметанин Виктор Николаевич \\ кандидат медицинскх наук, доцент, \\ дочент кафедры эпидемиологии Рязанского государственного \\ медицинского университета имени академика И.П. Павлова, \\ 390026 г. Рязань, ул. Высоковольтная, д. 9 \\ Кирюшин Валерий Анатольевич \\ доктор медицинских наук, профессор, \\ заведующий кафедрой профильных гигиенических дисияиплин с \\ курсом гигиены, эпидемиологии и организаџии госсанэпидслужбы ФДПО \\ Рязанского государственного медицинского университета \\ имени академика И.П. Павлова, \\ 390026 г. Рязань, ул. Высоковольтная, д. 9
}

\begin{abstract}
Аннотация. Компетентностный подхода в системе высшего профессионального образования обеспечивает улучшение взаимодействие с рынком труда и повышение конкурентоспособности специалистов, что требует обновление содержания образования и повышение качества профессионального обучения.

Annotation. A competent approach in the higher vocational education system provides an improved interaction with the labor market and improved the competitiveness of professionals, which requires updating the content of education and improving the quality of vocational training.

Ключевые слова: технологии, компетентностный подход, инфекционная безопасность, дополнительное профессиональное образование

Keywords: technology, competent approach, infectious safety, additional vocational education
\end{abstract}

Внедрение компетентностного подхода в систему высшего профессионального образования направлено на улучшение взаимодействия с рынком труда, повышение конкурентоспособности специалистов, обновление содержания, методологии и соответствующей среды обучения.

Основная цель профессионального образования - подготовка квалифицированного специалиста соответствующего уровня и профиля, конкурентоспособного на рынке труда, компетентного, свободно владеющего своей профессией и ориентирующегося в смежных областях деятельности, готового к постоянному профессиональному росту, социальной и профессиональной мобильности.

В качестве основания Федерального государственного стандарта (ФГОС) высшего образования по специальности 32.05.01. «Медико-профилактическое дело» (уровень специалитета) выступает компетентностный подход, направленный на обновление содержания образования и повышение качества профессионального обучения.

Смена методологических идей оказала влияние на изменение понятийного аппарата. Вместо привычных «знаний», «умений», «навыков» появились новые термины: «компетенция» и «компетентность».

Понятие «компетентность» подразумевает готовность (подготовленность) человека к выполнению той или иной социальной роли: профессионала, члена общества, гражданина и т. д. С этих позиций компетентность есть результат образования, а, следовательно, и цель, достижение которой обеспечивается реализацией требований стандарта.

Понятие «компетентность» следует отличать от понятия «компетенции», которые представляют обобщенные способы действий, обеспечивающие продуктивное выполнение профессиональной или иной деятельности. То есть компетенции обнаруживаются и проявляются в конкретных ситуациях, социальных и профессиональных обстоятельствах [1, с. 12-13].

В теории компетентностного подхода выделяют ключевые и функциональные компетенции.

Под ключевыми понимаются компетенции, необходимые для жизнедеятельности человека и связанные с его успехом в профессиональной деятельности в быстроизменяющемся обществе [1,2,3,4]. В этом смысле они становятся универсальными, широкого спектра действия. Э.Ф. Зеер [5] считает более правильно их называть базовыми компетенциями, поскольку они многофункциональны, междисциплинарны, надпредметны и первичны по отношению к другим. В стандартах третьего поколения ключевые компетенции обозначены как общие компетенции (ОК).

Функциональные (специальные) компетенции представляют собой совокупность характеристик определенной профессиональной деятельности и представляют собой набор функций конкретного рабочего места. В стандарте данная группа компетенций обозначена как профессиональные компетенции (ПК). 
Структурным элементом стандартов третьего поколения является не предмет, а образовательная область, представляемая в виде профессиональных модулей и междисциплинарных курсов, направленных на освоение обучающимися конкретных видов профессиональной деятельности. В свою очередь, структурными элементами профессиональных модулей становятся профессиональные (ПК) и общие (ОК) компетенции.

Методологический подход, положенный в основу новых стандартов, обусловливает изменения не только в построении образовательного процесса, но и оказывает влияние на использование педагогами иных форм, методов обучения и воспитания, поскольку формирование компетенций невозможно в рамках традиционных технологий, направленных на формирование знаний, умений и навыков.

На современном этапе развития общества и модернизации образования необходимо, чтобы слушатели были ориентированы на практическое применение полученных знаний, на анализ и критическое осмысление поступающей информации, на умения принимать профессиональные решения на основе творческой переработки полученных знаний. В связи с этим появляется необходимость использования активных и методов, форм и технологий обучения, обеспечивающих интенсивное развитие личности слушателя и преподавателя [6].

Прежде чем внедрять эту технологию в процесс обучения была проделана большая предварительная работа по изучению сущности технологии, опыта работы других образовательных учреждений, возможности использования технологии в зависимости от особенностей дисциплины. Результатом этой работы можно считать разработанные методические подходы к использованию технологии контекстного обучения, которые и будут представлены ниже.

Традиционное обучения ориентировано на усвоение знаковой учебной информации и чем больше ее усвоено, тем выше считается уровень образованности. В традиционной практике слушатель получает знания, которые оторваны от смыслообразующих контекстов его будущей специальности. Сейчас происходит стремительное обновление оборудования и технологий оказания медицинской помощи, а мы учим как бы с опозданием, отстаем от динамики в развитии специальности. Обучение же тогда ценно, когда оно учит с опережением, готовит специалиста к завтрашнему дню.

Кроме того, цели, которые ставятся слушателям при обучении, задаются обществом (требования ФГОС), преподавателем, но не самим слушателем. Поэтому учение и теряет для них смысл, ведь задачи и цели поставлены не самими слушателями, а навязаны извне.

В технологии контекстного обучения необходимо также уяснить разницу между содержанием обучения и содержанием образования. Содержание обучения определяется ФГОС по специальности, учебными планами и программами. В отличие от содержания обучения содержание образования отражает уровень развития личности, предметной и социальной компетентности слушателя, который формируется в процессе обучения. Меняется «образ» личности и цель образования - развитие личностного потенциала. Базовым понятием контекстного обучения является категория контекста. Контекст связан с понятием «ситуация», т. е. системой условий, побуждающих субъекта к проявлению активности. В ситуацию включаются и внешние условия, и сам субъект, и те люди, с которыми он контактирует.

Прежде чем приступить к действию, человек старается собрать как можно больше контекстной информации. Если у человека нет образцов поведения, зафиксированных в определенных контекстах, например поведения в определенных производственных ситуациях, то он испытывает дискомфорт, даже страх и неумение спрогнозировать свои действия. Прогнозирование как необходимое умение основано на предвосхищении действий хотя бы на шаг. Следовательно, контекст может активизировать мышление слушателя и вводить его в состояние проблемной или творческой ситуации.

Учебный процесс в университете является одним из проявлений социальной практики. Следовательно, контексты жизни и будущей трудовой деятельности медицинского работника должны наполнить учебу личностным смыслом, определить меру включенности в познавательный процесс. Отсюда меняется и основная цель деятельности преподавателя: не обучение, а формирование целостной модели профессиональной деятельности слушателя.

Предмет учебной деятельности для слушателя всегда абстрактен, им являются тексты, схемы, макеты, методические указания. В реальном же предмете будущей профессиональной деятельности знания даны в контексте технологических процессов и ситуаций. Продуктивное мышление - это обращение к новому, к тем неизвестным, нестандартным и проблемным ситуациям, которые возникнут у него в производственной деятельности. Следовательно, информация на занятии должна даваться в контексте будущей деятельности, с направленностью будущего профессионального использования: где, когда и как можно применить эти знания?

Одним из условий, создающим оптимальный процесс обучения по вопросам инфекционной безопасности является вовлечение обучающихся в определение своих собственных потребностей в знаниях по этому разделу, что стимулирует внутреннюю мотивацию к получению знаний и навыков.

Таким образом, слушателю задаются рамки его профессионального труда. Основой взаимодействия преподавателя и слушателя становится ситуация во всей ее предметной и социальной неоднозначности. Именно в ходе анализа ситуаций, деловых и учебных игр слушатель формируется как специалист и член будущего коллектива. 
В технологии контекстного обучения используются три базовые формы деятельности: учебная деятельность с ведущей ролью лекций и семинаров; квазипрофессиональная - игры, тренинги; учебно-профессиональнаяУИРС, производственная практика.

В соответствии с этими формами можно реализовать три модели обучения. Модели первого типа включают систему заданий, предполагающих работу с текстом и переработку знаковой информации. Единицей работы студента являются действия слушания и говорения, чтение, письмо. В моделях второго типа учебные задания будут выходить за рамки знаковой информации и соотносится с будущей профессиональной деятельностью. В этом случае единицей работы оказывается предметное действие. Учебная деятельность слушателя опирается на контекст. В моделях же третьего типа задания выполняются в совместных, коллективных формах. Такие совместные поиски решения проблемы формируют опыт коллективной работы в будущей профессиональной среде. Эта модель реализуется в деловых и учебных играх, УИРС, в выполнении профессиональной задачи на междисциплинарном экзамене.

Таким образом, образование в технологии контекстного обучения предполагает два компонента: предметное содержание, которое обеспечивает профессиональную компетентность слушателя, и социальное, обеспечивающее способность работать в коллективе, быть коммуникабельной и социально зрелой личностью.

На семинарских занятиях изучаются директивные документы, отражающие вопросы инфекционной безопасности и инфекционного контроля в условиях деятельности медицинских организаций.

При решении ситуационных задач слушатели самостоятельно оценивают состояние инфекционной безопасности на конкретных примерах и разрабатывают меры по предупреждению распространения внутрибольничных инфекций.

Необходимость внедрения новых форм постдипломного образования определяется тем, что при существующей системе обучения полученные знания плохо трансформируются в умения и практику применения навыков по инфекционной безопасности и профилактике ИСМП и улучшению результатов лечения больных.

Сочетание познавательного интереса и позитивной мотивации, характерное для контекстного обучения, способствует трансформации познавательных мотивов в профессиональные, что ведет к постепенному превращению учебной деятельности в реальную предметную деятельность.

Таким образом, формирование профессиональной компетентности в постдипломном образовании возможно посредством внедрения технологии контекстного обучения.

\section{Библиография}

1.Безюлева Г. В. Профессиональная компетентность: аспекты формирования. М.: МПСИ, ФИРО, 2005. 82 с.

2.Вербицкий А. А. Контекстно-компетентностный подход к модернизации образования // Высшее образование в России. 2010. № 5. С. 32-37.

3.Вербицкий А. А., Ларионова О.Г. Личностный и компетентностный подходы в образовании: проблемы интеграции. М.: Логос, 2009. 336 с.

4. Вербицкий, А. А. Контекстное обучение: теория и технологии / Новые методы и средства обучения.- 2009.№2 .- С 51-54

5.Зеер Э. Ф., Павлов А. М. Модернизация профессионального образования:

компетентностный подход. М.: Изд-во МПСИ, 2005. $211 \mathrm{c.}$

6. Лаврентьев, Г. В. Инновационные обучающие технологии в профессиональной подготовке специалистов / Г. В. Лаврентьев, Н. Б. Лаврентьева, Н. А. Неудахина. - Барнаул: Изд-во АлтГУ, 2004. - 184 с.

7. Концепция Федеральной целевой программы развития образования на 2016 - 2020 годы (утв. распоряжением Правительства РФ от 29 декабря 2014 г. № 2765-p). Электронный доступ. URL: http://www.garant.ru/products/ipo/prime/doc/55070647/

8. Троянская С.Л. Основы компетентностного подхода в высшем образовании: учебное пособие. - Ижевск: Издательский центр «Удмуртский университет», 2016 - 176 с.

9. Федоров А.Э., Компетентностный подход в образовательном процессе /А.Э.Федоров, С.Е. Метелев, А.А.Соловьев, Е.В. Шлякова-Омск-.2012.- 210 с. 